\title{
COMPOSIÇÃO CENTESIMAL E TEOR DE NITRATO EM CINCO CULTIVARES DE ALFACE PRODUZIDAS SOB CULTIVO HIDROPÔNICO $\left({ }^{1}\right)$
}

\author{
SILVANA OHSE $\left({ }^{2 *}\right)$; DIVA MARIA RAMOS RAMOS $\left({ }^{3}\right)$; SABRINA MATOS DE CARVALHO $\left({ }^{4}\right)$; \\ ROSEANE FETT $\left({ }^{4}\right)$; JORGE LUIZ BARCELOS OLIVEIRA $\left({ }^{3}\right)$
}

\begin{abstract}
RESUMO
Com o objetivo de avaliar a qualidade nutricional de cinco cultivares de alface (Mimosa Verde, Mimosa Vermelha, Vera, Regina e Lucy Brown) produzidas em cultivo hidropônico sob sistema NFT, determinou-se sua composição centesimal e seu teor de nitrato. $\mathrm{O}$ delineamento experimental utilizado foi o inteiramente casualizado com quatro repetições. O experimento foi desenvolvido no Departamento de Engenharia Rural da Universidade Federal de Santa Catarina, Florianópolis (SC), de maio a julho de 2004. As bancadas de produção possuíam sete canais com 6,0 m de comprimento e 1,50 m de largura. O espaçamento utilizado foi 0,25 m e canais e 0,25 m entre plantas no canal. A colheita foi efetuada aos 54 dias após a semeadura, e permanência por 24 dias na bancada de produção. Na cultivar de alface do tipo americana, Lucy Brown, observou-se maior teor de água da parte aérea e também maior teor de nitrato. Nas cultivares Mimosa Vermelha e Mimosa Verde verificaram, em média, maior teor de fitomassa seca da parte aérea, de lipídios, de proteína e maior valor calórico. Na cultivar Mimosa Vermelha constatou-se maior teor de carboidratos e na Mimosa Verde, o maior teor de resíduo mineral, não diferindo da cultivar Regina. O maior teor de fibra foi constatado na cultivar Regina.
\end{abstract}

Palavras-chave: hidroponia, Lactuca sativa L., nitrato e composição centesimal.

\section{ABSTRACT \\ CENTESIMAL COMPOSITION AND NITRATE CONTENT IN FIVE CULTIVARS OF LETTUCE PRODUCED IN HYDROPONIC SYSTEM}

The nutrition quality of five different lettuce cultivars (Mimosa Verde, Mimosa Vermelha, Vera, Regina and Lucy Brown) produced under NFT (Laminar Flow of Solution) system was determined by their centesimal composition and nitrate content. To analyze the experimental treatments it was used a completely randomized design with four replications. The experiment was developed in a greenhouse belonging to the Department of Agricultural Engineering of the Federal University of Santa Catarina, Florianópolis, Santa Catarina State, Brazil, from May to July of 2004 (autumn-winter period). The lettuces were grown in a group of benches (3\% declivity) with seven canals $(6.0 \mathrm{~m}$ length and $1.50 \mathrm{~m}$ width) where the nutritional solution would circulate. The space used was $0.25 \mathrm{~m}$ between canals and $0.25 \mathrm{~m}$ between plants in the canal, thus in each canal 24 plants had been lodged, totalizing 168 per bench. The circulation of the nutritional solution was controlled by a timer, which set in motion the joint motion-bomb in intervals preset in a turn 24-hour. The harvest was effected 54 days after the sowing, having remained per 24 days in the production group of benches. The American type of lettuce 'Lucy Brown', also presented a greater water content in its shoot as well as nitrate content than the others. Mimosa Vermelha and Mimosa Verde cultivars had on average, greater dry mass content theirs of shoots, as well as lipids, protein and caloric value than the others. 'Mimosa Vermelha' presented greater carbohydrates content and 'Mimosa Verde' the greater mineral residue content, but not differing from Regina cultivar. The biggest fiber content was presented by 'Regina'.

Key words: hydroponic, Lactuca sativa L., nitrate and centesimal composition.

( $\left.{ }^{1}\right)$ Recebido para publicação em 7 de dezembro de 2007 e aceito em 11 de fevereiro de 2009.

$\left({ }^{2}\right)$ Departamento de Fitotecnia e Fitossanidade, Universidade Estadual de Ponta Grossa, 84030-900 Ponta Grossa (PR). E-mail: sohse@uepg.br $\left(^{*}\right)$ Autora correspondente.

$\left({ }^{3}\right)$ Departamento de Engenharia Rural, UFSC/CCA, Florianópolis, Santa Catarina, Brasil.

$\left({ }^{4}\right)$ Departamento de Tecnologia dos Alimentos, Universidade Federal de Santa Catarina, Farmacêutica. 


\section{INTRODUÇÃO}

A alface é a hortaliça mais consumida pelos brasileiros e, devido a sua baixa resistência ao transporte e alta perecibilidade, é produzida próximo aos grandes centros de consumo. Dessa forma, sua produção, através do sistema hidropônico (NFT), vem crescendo a cada ano, uma vez que a alface é uma das hortaliças que atinge mais rapidamente o ponto de comercialização, com maior rendimento, ocupando pequenas áreas e fornecendo rápido retorno financeiro (SANTOS, 2000).

O consumo dessa hortaliça tem aumentado não só pelo crescente aumento da população, mas também, pela tendência de mudança no hábito alimentar por parte do consumidor. Vem sendo recomendado na dieta alimentar de pessoas em tratamento da obesidade e de doenças crônicodegenerativas (doenças cardiovasculares, diabetes mellitus e câncer) por seu baixo valor calórico (SANTOS et al., 1988; Martins e Riella, 1993). Por outro lado, a exigência do consumidor também aumentou, havendo necessidade de se produzir em quantidade e qualidade, bem como manter o fornecimento o ano todo. Devido a essa tendência do mercado hortícola é que o cultivo protegido (túneis e estufas) vem aumentando a cada ano, assim como os cultivos hidropônicos. Esse sistema vem ganhando grande espaço no país, principalmente próximo dos grandes centros urbanos.

Composição centesimal é a quantificação em porcentagem dos componentes de um determinado produto, estando entre esses componentes a água, proteína, carboidratos ou glicídios, lipídios, fibra e resíduo mineral ou cinzas. In natura a alface produzida no solo possui, segundo SGARBIERI (1987), a seguinte composição média, por 100 g comestíveis: água: 94\%; valor calórico: $18 \mathrm{kcal}$; proteína: 1,3 g; gordura: $0,3 \mathrm{~g}$; carboidratos totais: $3,5 \mathrm{~g}$; fibra: $0,7 \mathrm{~g}$; cálcio: $68 \mathrm{mg}$; fósforo: $27 \mathrm{mg}$; ferro: $1,4 \mathrm{mg}$; potássio: $264 \mathrm{mg}$; vitamina A: $1900 \mathrm{UI}$; tiamina: 0,05 mg; riboflavina: 0,08 $\mathrm{mg}$; niacina: 0,4 $\mathrm{mg}$; vitamina C: 18,0 mg. Portanto, a importância da alface é indiscutível por ser boa fonte de vitaminas e sais minerais para a alimentação humana.

Apesar da contribuição dos vegetais para a saúde humana, seu consumo é preocupante quando produzido com técnicas que comprometem a qualidade final do produto, como por exemplo, a presença de resíduos de pesticidas e teores altos de nitrato (SANTAMARIA e Elia, 1997).

Juntamente com a água potável, as hortaliças representam as principais fontes alimentares fornecedoras de nitrato para o organismo humano, principalmente nos países do norte da Europa. Nessa região, nos cultivos de outono e inverno o acúmulo de nitrato é favorecido em espécies oleráceas (alface, espinafre, rúcula, entre outras) (GraIFENBERG et al., 1993). Segundo KNIGHT et al. (1987), as principais fontes de nitrato para o homem são os vegetais, chegando a $90 \%$ do total ingerido. Este valor varia de acordo com os hábitos alimentares característicos de cada região. LAITINEN et al. (1993) revelaram que $86 \%$ da ingestão de nitrato $\left(\mathrm{NO}_{3}{ }^{-}\right)$pelos finlandeses advêm dos vegetais, com um consumo diário de $54 \mathrm{mg}$ de $\mathrm{NO}_{3}{ }^{-}$por pessoa.

Os nitratos e nitritos contribuem para a formação endógena de compostos nitrosos, tais como $\mathrm{N}$-nitrosaminas e N-nitrosamidas, potencialmente carcinogênicos e capazes de transformar a hemoglobina do sangue em ferrihemoglobina, processo que leva ao impedimento do transporte de oxigênio dos alvéolos pulmonares para os tecidos. Enquanto este mecanismo é reversível em pessoas adultas, pode levar lactentes à morte, principalmente crianças com menos de três meses de idade, pela deficiência fisiológica transitória de metemoglobina redutase ou de seu co-fator NADH (WRIGHT e Davinson, 1964; WolfF e Wasserman, 1972; SWANn, 1975; Araújo e Midio, 1989; WalKer, 1990; Macknight et al., 1999). Assim, o teor de nitrato é um importante índice da qualidade dos alimentos.

Por essa razão, houve grande preocupação em se estabelecer limites máximos de nitrato em hortaliças, uma vez que altos teores de nitrato são acumulados quando do uso de adubação nitrogenada excessiva, independentemente da fonte de adubo ser mineral ou orgânica (Richardson e HaRdgrave, 1992).

Castro e Ferraz (1998), utilizando lodo de esgoto como fonte de nitrogênio constataram $1.090 \mathrm{mg}$ $\mathrm{NO}_{3}{ }^{-} \mathrm{kg}^{-1}$ de fitomassa fresca (FMF) e $420 \mathrm{mg} \mathrm{NO}_{3}{ }^{-} \mathrm{kg}^{-}$ ${ }^{1}$ de FMF com uso de uréia. Segundo BERNARDES (1997) e Carmello (1996), a faixa de concentração de nitrogênio usada em soluções nutritivas recomendadas para o cultivo de alface em hidroponia no mundo varia de 100 a $300 \mathrm{mg} \mathrm{L}^{-1}$.

A comunidade européia estabeleceu como limite máximo permitido para alface produzida em estufa, teores de nitrato na fitomassa fresca de 3.500 $\mathrm{mg} \mathrm{kg}^{-1}$ para o período de verão $\left(1 .^{\circ}\right.$ de abril a 30 de setembro), $4.500 \mathrm{mg} \mathrm{kg}^{-1}$ para o período de inverno (1. de outubro a 31 de março) e $2.500 \mathrm{mg} \mathrm{kg}^{-1}$ o limite máximo permitido para alface produzida em campo aberto (Mccall e Willumsen, 1998). Na Alemanha, o limite é de $2.000 \mathrm{mg} \mathrm{kg}^{-1}$ de FMF, na Áustria é 1.500 $\mathrm{mg} \mathrm{kg}^{-1}$ de FMF e na Suíça é $875 \mathrm{mg} \mathrm{kg}^{-1}$ de FMF. Já Graifenberg et al. (1993), na Itália, consideram genótipos de alface com alto conteúdo de $\mathrm{NO}_{3}{ }^{-}$quando 
esse valor chega a $1.000 \mathrm{mg} \mathrm{kg}^{-1}$ de FMF. As variações encontradas, não só se devem aos efeitos dos diversos fatores que regulam o acúmulo de nitrato nas plantas, mas também à variação dos métodos utilizados para a análise de nitrato.

Os limites máximos permitidos não estão definidos e são muito divergentes entre diversos autores e países, mas a Organização Mundial para Agricultura e Alimentação (FAO) e a Organização Mundial da Saúde (OMS) estabeleceram como admissível a dose diária de $3,65 \mathrm{mg}$ do íon nitrato e $0,133 \mathrm{mg}$ do íon nitrito por $\mathrm{kg}$ de peso corporal. O limite aceitável de ingestão diária segundo, Corré e Breimer (1979) apud Van Der Boon et al. (1990) é de $220 \mathrm{mg}$. Escoín-Peña et al. (1998) consideram como limite máximo de consumo diário 3,6 $\mathrm{mg}$ de $\mathrm{NO}_{3}{ }^{-} \mathrm{kg}^{-1}$ de peso corporal e para crianças, menos de $10 \%$ deste valor. Croll e Hayes (1988) também recomendam que o teor de nitrato na água de consumo seja inferior a $50 \mathrm{mg} \mathrm{L}^{-1}$.

A produção e o consumo de alface produzida através da técnica do fluxo laminar de solução (NFT) têm aumentado consideravelmente, devido ao seu melhor aspecto visual, sua maior durabilidade e facilidade na limpeza. No entanto, pouco se sabe sobre a qualidade nutricional do produto final, tanto em relação ao acúmulo de nitrato como em relação à sua composição centesimal quando produzidas através dessa técnica. $\mathrm{O}$ trabalho teve por objetivo determinar a composição centesimal, o valor calórico e o teor de $\mathrm{NO}_{3}{ }^{-}$em cinco cultivares de alface produzidas sob hidroponia.

\section{MATERIAL E MÉTODOS}

O presente trabalho foi desenvolvido no Laboratório de Agricultura Irrigada e Hidroponia (LabHidro) do Departamento de Engenharia Rural, Universidade Federal de Santa Catarina (UFSC), localizada no município de Florianópolis (SC), durante o período de 15 de maio a 7 de julho de 2004.

Os tratamentos constaram de cinco cultivares de alface: Regina, Vera, Mimosa Vermelha, Mimosa Verde e Lucy Brown (Americana), utilizando-se para seu cultivo o sistema hidropônico NFT (Nutrient Film Tecnique ou fluxo laminar de solução). O delineamento experimental foi o inteiramente casualizado com quatro repetições.

A semeadura foi realizada em 15 de maio de 2004 em espuma fenólica previamente lavada, a qual foi submetida a um período de 24 horas no escuro, buscando-se obter temperatura uniforme e, assim, homogeneidade na germinação. Posteriormente, foram transferidas para um sistema chamado tanque de produção de mudas ou "maternidade".
O tanque de produção de mudas constou de uma bancada com $3 \%$ de declividade, $2 \mathrm{~m}$ de comprimento, 1,2 m de largura e $0,9 \mathrm{~m}$ de altura, a qual foi feita com uma chapa de zinco, dividida em três partes e recoberta com plástico dupla face (branco e preto), com a parte branca voltada para cima, contendo reservatório próprio com capacidade de 250 L. Na maternidade, a solução nutritiva foi diluída até a concentração dos nutrientes atingir $50 \%$ do citado na tabela 1. Para efetuar a circulação da solução foi utilizada uma bomba de aquário, a qual foi acionada por um timer, irrigando quatro vezes ao dia as espumas fenólicas contendo as mudas.

Tabela 1. Composição química da solução nutritiva utilizada. UFSC, Florianópolis (SC), 2004

\begin{tabular}{lc}
\hline Fertilizantes Minerais & $\mathrm{g} 1000 \mathrm{~L}^{-1}(100 \%)$ \\
\hline $\mathrm{Ca}\left(\mathrm{NO}_{3}\right)_{2} \cdot 6 \mathrm{H}_{2} \mathrm{O}$ & 800,0 \\
$\mathrm{MAP}^{*}$ & 109,1 \\
$\mathrm{MKP}^{* *}$ & 63,3 \\
$\mathrm{KNO}_{3}$ & 460,2 \\
$\mathrm{MgSO}_{4} \cdot 7 \mathrm{H}_{2} \mathrm{O}$ & 418,9 \\
$\mathrm{MnSO}_{4} \cdot \mathrm{H}_{2} \mathrm{O}$ & 1,48 \\
$\mathrm{ZnSO}_{4} \cdot 7 \mathrm{H}_{2} \mathrm{O}$ & 0,39 \\
$\mathrm{CuSO}_{4} \cdot 5 \mathrm{H}_{2} \mathrm{O}$ & 0,10 \\
$\mathrm{H}_{3} \mathrm{BO}_{3}$ & 2,63 \\
$\mathrm{Na}_{2} \mathrm{MoO}_{4} \cdot 2 \mathrm{H}$ & $\mathrm{O}$ \\
$\mathrm{Tenso}_{-} \mathrm{Fe}(\mathrm{Fe}-\mathrm{EDDHMA})$ & 0,17 \\
\hline
\end{tabular}

${ }^{*} \mathrm{MAP}=$ Monofosfato de amônio. ${ }^{* *} \mathrm{MKP}=$ Monofosfato de potássio.

Ao atingirem quatro a cinco folhas desenvolvidas, as mudas foram retiradas da maternidade. Efetuou-se a divisão das células da espuma fenólica, selecionaram-se as melhores mudas e, quando necessário, fez-se o raleio (Mimosa Vermelha e Mimosa Verde), transferindo-as para a fase intermediária ou berçário. Nessa fase, utilizou-se a solução descrita na tabela 1 .

A bancada possuía 3\% de declividade, $6 \mathrm{~m}$ de comprimento por $2 \mathrm{~m}$ de largura e altura de $0,9 \mathrm{~m}$. Os tubos utilizados foram produzidos pela Hidrogood, perfil pequeno $50 \mathrm{~mm}$ de polipropileno (PP), material atóxico, colocados lado a lado sobre a bancada. A circulação da solução nutritiva foi controlada por um timer, que acionou o conjunto motobomba em intervalos preestabelecidos em um turno de 24 horas. Durante o dia (6h às $17 \mathrm{~h} 30 \mathrm{~min})$, houve circulação intermitente da solução com intervalos de 10 minutos e à noite, circulação por 10 minutos às $20 \mathrm{~h}, 23 \mathrm{~h}$, 4 h30min. 
Do reservatório, a solução nutritiva era recalcada para a parte superior da bancada pelo conjunto motobomba de 1,0 HP, fornecendo solução nutritiva para cada canal na vazão de 1,5 litros por minuto, passando pelos canais e recolhida, na parte inferior da bancada por um canal coletor; a solução, então, retornava ao reservatório, enterrado externamente à casa-de-vegetação sob cobertura de telha transparente pintada de branco, buscando-se evitar o aquecimento da solução. Nesta fase intermediária, entre a maternidade e a produção final, buscou-se melhorar o desenvolvimento do sistema radicular e adaptar as plantas ao sistema NFT.

A bancada de produção final constou de duas bancadas, sustentadas por cavaletes de madeira, com $0,9 \mathrm{~m}$ de altura, sobre os quais foram colocados sete canais de cultivo, com declividade de $3 \%$ e $6 \mathrm{~m}$ de comprimento. O espaçamento utilizado foi de $25 \mathrm{~cm}$ entre canais e $25 \mathrm{~cm}$ entre plantas nos canais, em uma distribuição triangular, em orifícios de $3,0 \mathrm{~cm}$ de diâmetro. Em cada canal, alojaram-se 24 plantas, totalizando 168 por bancada. A quantidade de solução por planta foi de 1,0 litro.

A circulação da solução nutritiva foi controlada por timer de forma idêntica ao efetuado na fase intermediária. O volume do reservatório era completado diariamente, corrigindo-se o $\mathrm{pH}$ para 5,8 $\pm 0,5$, utilizando-se $\mathrm{H}_{2} \mathrm{SO}_{4} 1 \mathrm{M}$ e $\mathrm{NaOH} 1 \mathrm{M}$. Durante essa fase, efetuou-se a troca da solução a cada 7 dias, realizando-se correções sempre que a condutividade tornava-se inferior a $1,7 \mathrm{mS} \mathrm{cm}^{-1}$.

A semeadura foi feita em 15 de maio, passando para a maternidade em $16 / 5$. As mudas foram transferidas para a fase intermediária em 29 de maio e, para a bancada final, em 12 de junho, onde permaneceram por 24 dias, perfazendo 54 dias de ciclo.

Foram amostradas quatro plantas por cultivar, pesadas e colocadas em sacos de papel para secagem em estufa de ventilação forçada de ar a $55{ }^{\circ} \mathrm{C}$. Após atingir fitomassa constante a parte aérea das plantas foi moída para a determinação do teor de nitrato, segundo método descrito por CATALDo et al. (1975) e para a análise da composição centesimal (teor de água, resíduo mineral, lipídios, fibras, proteínas e carboidratos) segundo método sugerido por MORETTO et al. (2002). O valor calórico foi calculado a partir dos teores da fração protéica, lipídica e carboidratos, utilizando-se os coeficientes específicos que levam em consideração o calor de combustão 4,0; 9,0 e 4,0 kcal respectivamente.

Os dados obtidos foram submetidos à análise da variância. Quando houve efeito de tratamento, efetuou-se a comparação das médias pelo teste de
Tukey com 5\% de probabilidade. Os dados de teor de água e de fitomassa seca da parte aérea foram transformados em arco seno $\sqrt{x / 100}$.

\section{RESULTADOS E DISCUSSÃO}

A análise da variância revelou diferença estatística significativa para as variáveis da composição centesimal (teor de água, de fibra, de lipídios, de glicídios, de proteína e de cinza ou resíduo mineral), valor calórico e teor de nitrato.

As cultivares de alface acumularam diferentes teores de nitrato na parte aérea. Na cultivar Lucy Brown (alface americana) ocorreu o maior acúmulo de nitrato, diferindo significativamente das demais, e a cultivar Vera, o menor valor, sem diferir de Mimosa Vermelha (Tabela 2).

FERNANDES et al. (2002) relatam teores de nitrato de $1.082 \mathrm{mg} \mathrm{kg}^{-1}$ de FMF para a cultivar Grandes Lagos e $1.092 \mathrm{mg} \mathrm{kg}^{-1}$ de FMF para a cultivar Regina, teores muito superiores aos constatados neste estudo para as cinco cultivares testadas, porém com algumas diferenças na solução nutritiva. Teores superiores foram obtidos também por OHSE et al. (2001a), cuja média foi de $690 \mathrm{mg} \mathrm{NO}_{3}^{-} \mathrm{kg}^{-1}$ de FMF em alface produzida convencionalmente, coletada em 10 propriedades rurais de Santa Maria (RS).

Abd-Elmoniem et al. (1996) relataram que folhas de alface retêm menor acúmulo de nitrato com o fornecimento de $\mathrm{N}$ na forma de $\mathrm{NH}_{4}{ }^{+}{\mathrm{e} \mathrm{NO}_{3}}^{-}$, quando comparadas àquelas de nutrição exclusiva com $\mathrm{N}$ $\mathrm{NO}_{3}{ }^{-}$. Com o aumento do fornecimento de $\mathrm{N}$ na forma de $\mathrm{NO}_{3}{ }^{-}$, a capacidade de redução do nitrato nas raízes torna-se um fator limitante e há aumento da proporção de $\mathrm{N}$-total translocado para a parte aérea na forma de $\mathrm{NO}_{3}^{-}$(MARSCHNER, 1995).

OHsE et al. (2002) verificaram em alface, em cultivo hidropônico durante o inverno, maior acúmulo de nitrato na cultivar Regina quando da utilização da solução nutritiva de Castellane e Araújo, o qual foi de 989,3 $\mathrm{mg} \mathrm{NO}_{3}{ }^{-} \mathrm{kg}^{-1}$ de FMF e, menor teor quando do uso da solução nutritiva de Ueda na cultivar Verônica (151,9 $\mathrm{mg} \mathrm{NO}_{3}^{-} \mathrm{kg}^{-1}$ de FMF). Comparando seis cultivares de alface cultivadas durante a primavera, OHSE et al. (2004) obtiveram teores de nitrato variando de 336,9 a $259,38 \mathrm{mg} \mathrm{kg}^{-1}$ de FMF, valores inferiores somente aos obtidos para a cultivar Lucy Brown (Tabela 2). Neste trabalho, o maior teor de nitrato foi observado na cultivar Lucy Brown (alface americana), seguido da cultivar Regina, podendo-se suspeitar que essas cultivares possuem característica genética para maior acúmulo de nitrato, entre as cultivares testadss e mesmo entre os resultados revelados na literatura. 
Tabela 2. Teor de água da parte aérea (TAPA), teor de fitomassa seca da parte aérea (TFMSPA), teor de nitrato na fitomassa seca $\left(\mathrm{TNO}_{3}{ }^{-}\right.$na FMS) e teor de nitrato na fitomassa fresca $\left(\mathrm{TNO}_{3}{ }^{-}\right.$na FMF) de cinco cultivares de alface produzidas sob cultivo hidropônico aos 54 dias após a semeadura. UFSC, Florianópolis (SC), 2004

\begin{tabular}{lcccc}
\hline Tratamentos & TAPA & TFMSPA & TNO $_{3}{ }^{-}$na FMS & TNO ${ }^{-}$na FMF \\
\cline { 2 - 3 } Lucy Brown & $96,03 \mathrm{a}$ & $3,97 \mathrm{~d}$ & $8.964,25 \mathrm{a}$ & $441,40 \mathrm{a}$ \\
Mimosa Verde & $95,01 \mathrm{~d}$ & $5,00 \mathrm{a}$ & $714,25 \mathrm{~d}$ & $40,90 \mathrm{~d}$ \\
Mimosa Vermelha & $95,09 \mathrm{~d}$ & $4,91 \mathrm{a}$ & $1.112,75 \mathrm{~cd}$ & $64,88 \mathrm{~cd}$ \\
Regina & $95,47 \mathrm{c}$ & $4,53 \mathrm{~b}$ & $2.602,50 \mathrm{~b}$ & $142,59 \mathrm{~b}$ \\
Vera & $95,58 \mathrm{~b}$ & $4,42 \mathrm{c}$ & $1.481,00 \mathrm{c}$ & $80,22 \mathrm{c}$ \\
Média & 95,43 & 4,56 & $2.974,95$ & 154,00 \\
\hline CV $(\%)$ & 0,04 & 0,90 & 16,10 & 16,10 \\
\hline
\end{tabular}

Médias de tratamentos seguidas por mesma letra na coluna não diferem entre si pelo teste de Tukey a 5\% de probabilidade de erro.

FAQUIN et al. (1996), utilizando a solução de Furlani, observaram 436,9 mg $\mathrm{NO}_{3}{ }^{-} \mathrm{kg}^{-1}$ de FMF na cultivar Verônica. OHSE et al. (2002) obtiveram teores médios de nitrato variando de 178,7 a 752,02 $\mathrm{mg} \mathrm{NO}_{3}^{-}$ $\mathrm{kg}^{-1}$ de FMF em função da solução nutritiva. RUSCHEL (1998) verificou teor máximo de $345 \mathrm{mg} \mathrm{NO}_{3}{ }^{-} \mathrm{kg}^{-1} \mathrm{de}$ FMF em alface hidropônica, quando a solução fornecia $240 \mathrm{mg} \mathrm{L}^{-1}$ de nitrogênio. Delistoianov et al. (1996), notaram máximo teor de nitrato na cultivar Tainá (1.688 $\mathrm{mg} \mathrm{NO}_{3}^{-} \mathrm{kg}^{-1}$ de FMF). Mondin (1996) observou em alface hidropônica o teor médio de 666,19 mg $\mathrm{NO}_{3}{ }^{-} \mathrm{kg}^{-1}$ de FMF aos 79 dias após a semeadura. Já REZENDE et al. (1999), analisando oito amostras de alface hidropônica em Brasília-DF, constataram teores de nitrato variando de 687 a $5.044 \mathrm{mg} \mathrm{NO}_{3}^{-} \mathrm{kg}^{-1}$ de FMF. Da mesma forma, JunQueIRA et al. (1999), analisando 20 amostras de alface hidropônica em duas propriedades em Brasília-DF, verificaram teores médios de 3.841 e $684 \mathrm{mg} \mathrm{NO}_{3}^{-} \mathrm{kg}^{-1}$ de FMF. BENINI et al. (2002) obtiveram para alface produzida em hidroponia, teor médio de nitrato de $1.588 \mathrm{mg} \mathrm{NO}_{3}{ }^{-}$ $\mathrm{kg}^{-1}$ de FMF, com valores máximo e mínimo de 2.568 e $471 \mathrm{mg} \mathrm{NO}_{3}^{-} \mathrm{kg}^{-1}$ de FMF respectivamente, e desviopadrão de $560 \mathrm{mg} \mathrm{NO}_{3}^{-} \mathrm{kg}^{-1}$ de FMF. Os resultados constatados por esses autores têm certa variação em função do manejo, condições climáticas, época do ano, horário de colheita, entre outros, todavia, não há grandes discrepâncias com os resultados aqui analisados (Tabela 2).

Na cultivar Lucy Brown observou-se o maior teor de água da parte aérea, com teor médio de 96,03\% e, consequentemente o menor teor de fitomassa seca da parte aérea $(3,97 \%)$ aos 54 dias após a semeadura (Tabela 2). O teor médio de água na parte aérea foi de $95,43 \%$, valor levemente maior a semelhante aos citados por Dutra de Oliveira e Marchini (1998) e SGARBIERI (1987) para alface cultivada no solo, os quais foram, respectivamente, de $94,85 \%$ e $94,0 \%$. Em alface hidropônica, MondiN (1996) verificou menores teores, de $92,7 \%$ e $92,1 \%$, respectivamente, aos 79 e 93 dias após a semeadura. Já Ruschel (1998), aos 47 dias após a semeadura, com 17 dias na bancada de produção, notou teor médio de $96,04 \%$. Essa variação no teor de água se deve, provavelmente ao tempo de permanência das plantas de alface na fase final, posto que, quanto maior esse período, maior o acúmulo de fitomassa seca e menor o teor de água.

As cultivares Mimosa Verde e Mimosa Vermelha proporcionaram os maiores teores de lipídios e a cultivar Lucy Brown (alface americana) o menor (Tabela 3). Os teores de 0,41 e 0,42 g $100 \mathrm{~g}^{-1} \mathrm{de}$ lipídios observados nas cultivares Mimosa Vermelha e Mimosa Verde foram superiores aos obtidos por OHSE et al. (2001b; 2001c e 2002), e a cultivar Lucy Brown

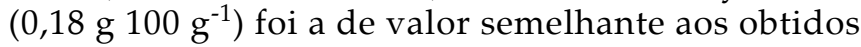
pelos referidos autores.

A cultivar Lucy Brown possui menor teor de

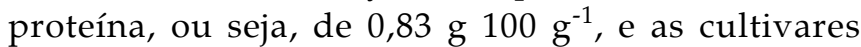
Mimosa Verde e Mimosa Vermelha atingiram os

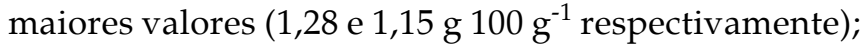
no entanto, a cultivar Mimosa Vermelha não diferiu significativamente da cultivar Regina (Tabela 3).

O maior teor de glicídios foi observado na cultivar Mimosa Vermelha e os menores valores para essa variável foram das cultivares Lucy Brown (do tipo americana) e Regina (Tabela 3).

Em alface cultivada no solo, DUtRA DE OLIVEIRA e MARChini (1998) citam teores de 0,1; 2,7; 1,0 g $100 \mathrm{~g}^{-1}$ e $13,0 \mathrm{kcal}$ para alface do tipo crespa e 0,$2 ; 2,9 ; 1,3 \mathrm{~g}$ $100 \mathrm{~g}^{-1}$ e $15,0 \mathrm{kcal}$ para alface do tipo lisa, respectivamente, para teores de lipídios, glicídios, proteína e valor calórico. 
Tabela 3. Teores de lipídio, proteína, carboidrato (Carb.), fibra, resíduo mineral (TRM) e valor calórico (V.Cal.) de cinco cultivares de alface produzidas sob hidroponia. UFSC, Florianópolis (SC), 2004

\begin{tabular}{|c|c|c|c|c|c|c|}
\hline Tratamentos & Lipídio & Proteína & Carb. & Fibra & TRM & V. Cal. \\
\hline & \multicolumn{5}{|c|}{ g $100 \mathrm{~g}^{-1}$ de produto integral } & kcal $100 \mathrm{~g}^{-1}$ \\
\hline Lucy Brown & $0,18 \mathrm{c}$ & $0,83 \mathrm{~d}$ & $1,99 \mathrm{c}$ & $0,34 \mathrm{~b}$ & $0,63 \mathrm{bc}$ & $12,90 \mathrm{~d}$ \\
\hline Mimosa Vermelha & $0,42 \mathrm{a}$ & $1,15 \mathrm{ab}$ & $2,43 \mathrm{a}$ & $0,25 \mathrm{c}$ & $0,66 \mathrm{bc}$ & $18,12 \mathrm{a}$ \\
\hline Mimosa Verde & $0,41 \mathrm{a}$ & $1,28 \mathrm{a}$ & $2,28 \mathrm{~b}$ & $0,26 \mathrm{c}$ & 0,77 a & $17,93 \mathrm{a}$ \\
\hline Regina & $0,25 \mathrm{~b}$ & $1,04 \mathrm{bc}$ & $2,06 \mathrm{C}$ & $0,48 \mathrm{a}$ & $0,70 \mathrm{ab}$ & $14,65 \mathrm{c}$ \\
\hline Vera & $0,26 \mathrm{~b}$ & $0,98 \mathrm{c}$ & $2,27 \mathrm{~b}$ & $0,30 \mathrm{bc}$ & $0,61 \mathrm{c}$ & $15,34 \mathrm{~b}$ \\
\hline Média & 0,30 & 1,06 & 2,21 & 0,32 & 0,67 & 15,79 \\
\hline CV (\%) & 4,74 & 5,99 & 2,48 & 8,01 & 5,23 & 1,35 \\
\hline
\end{tabular}

Médias de tratamentos seguidas por mesma letra na coluna não diferem entre si pelo teste de Tukey a de $5 \%$ de probabilidade de erro.

Os resultados aqui apresentados revelaram que, na cultivar do tipo Americana (Lucy Brown), ocorreram os menores teores de lipídios, glicídios, proteína e valor calórico, quando comparadas às cultivares de folha crespa (Vera, Mimosa Verde e Mimosa Vermelha). A cultivar Regina proporcionou maior teor de fibra (Tabela 3). SGARBIERI (1987) observou os seguintes valores médios para lipídios, glicídios, proteína e valor calórico: 0,3; 3,5; 1,3 g $100 \mathrm{~g}^{-1}$ e 18 kcal respectivamente, com superioridade em lipídios, glicídios e valor calórico, quando comparados aos resultados deste estudo. Já Martins e Riella (1993)

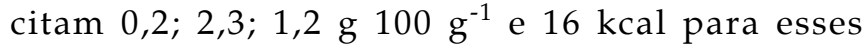
componentes. Desse modo, a alface hidropônica, independentemente do tipo de folha (lisa, crespa e americana), mantém a qualidade nutricional semelhante à alface produzida no solo, todavia, com algumas diferenças.

As cultivares estudadas acumularam diferentes teores de fibra na parte aérea (Tabela 3). A cultivar Regina foi o que de maior teor de fibra $(0,48$ g $\left.100 \mathrm{~g}^{-1}\right)$, diferindo significativamente $(\mathrm{a}=5 \%)$ das demais cultivares. Já os menores valores foram das cultivares Mimosa Vermelha e Mimosa Verde, não diferindo, no entanto, da cultivar Vera. O teor de fibra da cultivar Regina foi inferior aos teores obtidos por OHSE et al. (2001b), quando da produção hidropônica de seis cultivares, e para essa cultivar, o valor foi de

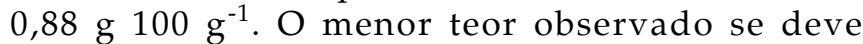
provavelmente ao menor ciclo de cultivo, à época do ano e às condições de cultivo (solução nutritiva, espaçamento etc.). Dutra de OliveIra e MarChini (1998) e SGARBIERI (1987) citam 0,6 e $0,7 \mathrm{~g} 100 \mathrm{~g}^{-1}$ como teores médios para alface produzida no solo. Percebe-se que os teores de fibra verificados em todas as cultivares de alface hidropônica foram menores que os da alface produzida no solo. Isso se deve, provavelmente, ao rápido ciclo de cultivo quando produzidas por esse sistema em casa de vegetação.
As cultivares de alface acumularam diferentes teores de resíduo mineral, sendo o maior teor de resíduo mineral proporcionado pela cultivar Mimosa Verde, o qual não diferiu significativamente da cultivar Regina (Tabela 3). OHSE et al. (2001b) obtiveram para a cultivar Mimosa Verde o valor de 0,93 g $100 \mathrm{~g}^{-1}$ e 0,87 g $100 \mathrm{~g}^{-1}$ de resíduo mineral para a cultivar Regina, quando produzidas em cultivo hidropônico em solução nutritiva sugerida por CASTELANE e ARAÚJO (1995), com valores superiores aos observados neste estudo (Tabela 3).

Nas cultivares Mimosa Verde e Mimosa Vermelha observou-se maior valor calórico e a cultivar Lucy Brown o menor (Tabela 3). OHsE et al. (2001b) obtiveram valor calórico médio de 13,19 kcal $100 \mathrm{~g}^{-1}$ para seis cultivares de alface produzidas sob cultivo hidropônico; nas cultivares Regina e Mimosa Verde, os valores foram de, respectivamente, 12,45 e 13,25 $\mathrm{kcal} 100 \mathrm{~g}^{-1}$. A média geral das cinco cultivares obtida neste trabalho foi de $15,79 \mathrm{kcal}_{100 \mathrm{~g}^{-1}}$, valor superior ao obtido por OHSE et al. (2001b), sendo maior para

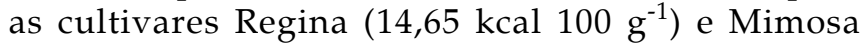

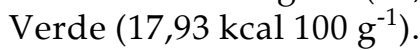

Apesar das diferenças em sua composição bioquímica, as cultivares de alface sob cultivo hidropônico são alimento saudável pelo teor de nitrato estar abaixo do teor considerado crítico pelos países europeus (2.500 mg NO${ }_{3}^{-} \mathrm{kg}^{-1}$ a $4.500 \mathrm{mg} \mathrm{NO}_{3}^{-} \mathrm{kg}^{-1}$ segundo McCall e WillumSEN, 1998).

\section{CONCLUSÕES}

1. Na cultivar de alface do tipo Americana, cultivar Lucy Brown, observou-se maior teor de água da parte aérea e também maior teor de nitrato.

2. As cultivares Mimosa Vermelha e Mimosa Verde, em média, proporcionaram maior teor de fitomassa seca da parte aérea, de lipídio, de proteína e maior valor calórico. 
3. Na cultivar Mimosa Vermelha, constatouse maior teor de carboidrato e na cv. Mimosa Verde, o maior teor de resíduo mineral, não diferindo da cultivar Regina.

4. O maior teor de fibra foi da cultivar Regina.

\section{REFERÊNCIAS}

ABD-ELMONIEM, E.M.; ABOU-HADID, A.F.; EL-SHINAWY, M.Z.; EL-BELTAGY, A.S.; EISSA, A.M. Effect of nitrogen form on lettuce plant grown in hydroponic system. Acta Horticulturae, Wageningen, v. 434, p. 47-52, 1996.

ARAÚJO, A.C.P.; MIDIO, A.F. Nitratos, nitritos e compostos $\mathrm{N}$-nitrosos em alimentos. Onde está o problema? Ciência e Cultura, Campinas, v.40, p.947-956, 1989.

BENINNI, E.R.Y.; TAKAHASHI, H.W.; NEVES, C.S.V.J.; FONSECA, I.C.B. Teor de nitrato em alface cultivada em sistemas hidropônico e convencional. Horticultura Brasileira, Brasília, v.20, n.2, p.183-186, 2002.

BERNARDES, L.J.H. Hidroponia da alface: uma história de sucesso. 1.ed. Charqueada: Estação Experimental de Hidroponia "Alface e Cia", 1997. 135p.

CARMELLO, Q.A.C. Cultivo hidropônico de plantas. 1.ed. Piracicaba: ESALQ/USP, 1996. 43p.

CASTELLANE, P.D.; ARAÚJO, J.A.C. Cultivo sem solo: Hidroponia. 4.ed. FCAV-UEP, Jaboticabal: FUNEP, 1995. 43p.

CASTRO, S.R.P.; FERRAZ, A.S.L. Teores de nitrato nas folhas e produção de alface cultivada com diferentes fontes de nitrogênio. Horticultura Brasileira, Brasília, v.16, n.1, p.65-68, 1998.

CATALDO, D.A.; HAROON, L.V.;SCHRADER, L.E.; YOUNGS, V.L. Rapid colorimetric determination of nitrate in plant tissue by nitration of salicilic acid. Communications in Soil Science and Plant Analysis,New York, v.6, n.1, p.71-80, 1975.

CROLL, B.T.; HAYES, C.R. Nitrate and wastes supplies in the United Kingdom. Environmental Pollution, Barking, v.50, p.163-187, 1988.

DELISTOIANOV, F.; PEREIRA, P.R.G.; MARTINEZ, H.E.P.; SEDIYAMA, C.S.; PAUL, P.A. Teores de nitrato em cultivares comerciais de alface sob cultivo hidropônico. Horticultura Brasileira, Brasília, v.14, n.1, p.84, 1996.

DUTRA DE OLIVEIRA, J.E.; MARCHINI, J.S. Ciências Nutricionais. 1.ed. São Paulo: Sarvier, 1998. 403p.

ESCOÍN-PEÑA, M.C.;IBANEZ, M.A.C.;SANTAMARTA, A.A.; LAZARO, R.C. Contenido de nitrato en lechugas y espinacas frescas. Agroalimentaria, Venezuela, v. 298, p.37-41, 1998.

FAQUIN, V.; FURTINI NETO, A.E.; VILELA, L.A.A. Produção de alface em hidroponia. 1.ed. Lavras: Minas Gerais, UFLA, $1996.50 \mathrm{p}$.
FERNANDES, A.A.; MARTINEZ, H.E.P.; PEREIRA, P.R.G; FONSECA, M.C.M. Produtividade, acúmulo de nitrato e estado nutricional de cultivares de alface, em hidroponia, em função de fontes de nutrientes. Horticultura Brasileira, Brasília, v.20, n.2, p.195-200, 2002.

GRAIFENBERG, A.; GIUSTINIANI, L.; TEMPERINI, O.; LIPUCCI DI PAOLA, M. La problematica dei nitrati. Informatore Agrario, Roma, v.6, p.43-48, 1993.

JUNQUEIRA, A.M.R.; REZENDE, A.J.; BORGO, L.A.; XIMENES, M.I.N. Níveis de nitrato em alface hidropônica e em agrião produzidos no Distrito Federal. In: CONGRESSO BRASILEIRO DE OLERICULTURA, 39. 1999. Tubarão. Anais... Tubarão: Sociedade Brasileira de Olericultura, 1999. v.1, n.153.

KNIGHT, T.M.; FORMAN, D.; AL-DABBAGH, S.A.; DOLL, P. Estimation of dietary intake of nitrate and nitrite in great britain. Food and Chemical Toxicology, Oxford, v.25, n.4, p.277$285,1987$.

LAITINEN, S.; VIRTANEN, S.M.; RÄSÄNEN, L.; PENTTILÄ, P.L. Calculated dietary intakes of nitrate and nitrite by young finns. Food Additivies and Contaminants, London, v.10, n.4, p.469-477, 1993.

MACKNIGHT, G.M.; DUNCAN, C.W.; LEIFERT, C.; GOLDEN, M.H. Dietary nitrate in man: friend or foe? British Journal of Nutrition, Cambridge, v.5, p.349-358, 1999.

MARSCHNER, H. Mineral nutrition of higher plants. 2ed. New York: Academic Press, 1995. 889 p.

MARTINS, C.; RIELLA, M.C. Composição e valor nutritivo dos alimentos. In: RIELLA, M.C. Suporte Nutricional Parenteral e Enteral. 2ed. Rio de Janeiro: Guanabara Koogan, 1993. p. 416-431.

McCALL, D.; WILLUMSEN, J. Effects of nitrate, ammonium and chloride application on the yield and nitrate content of soil-grown lettuce. Journal of Horticultural Science e Biotechnology, Ashford, v. 73, n. 5, p. 698-703, 1998.

MONDIN, M. Efeito de sistema de cultivo na produtividade e acúmulo de nitrato em cultivares de alface. 1996. 88p. Tese (Doutorado em Agronomia) - Faculdade de Ciências Agrárias e Veterinárias-UNESP, Jaboticabal.

MORETTO, E.; FETT, R.; GONZAGA, L.V.; KUSKOSKI, E.M. Introdução à ciência de alimentos. 1.ed. Florianópolis: Editora da UFSC, 2002. 255p.

OHSE, O.; DOURADO-NETO, D.; MARODIN, V.S.; DURANTE, E.C. Composição centesimal, teor de vitamina $C$ e de nitrato em seis cultivares de alface produzidos em quatro soluções hidropônicas. Revista Insula, Florianópolis, n.31, p. 59-79, 2002.

OHSE, O.; DOURADO-NETO, D.; MARODIN, V.S.; MANFRON, P.A.; AITA, A. Teores de nitrato e de vitamina $C$ em alface produzida em Santa Maria/RS: um estudo preliminar. Revista Insula, Florianópolis, n.30, p. 63-73, 2001a. 
OHSE, O.; DOURADO-NETO, D.; MARODIN, V.S.; MANFRON, P.A.; AITA, A.Composição centésima e teores de vitamina $C$, cálcio e fósforo de seis cultivares de alface produzidos sob dois sistemas de cultivo. Revista Insula, Florianópolis, n.30, p. 47-62, 2001b.

OHSE, O.; DOURADO-NETO, D.; MARODIN, V.S.; SANTOS, O.S. Qualidade de cultivares de alface produzidos em hidroponia. Scientia Agricola, Piracicaba, v. 58, n.1, p. 181$185,2001 c$

OHSE, O.; NOGUEIRA-FILHO, H.; DOURADO-NETO, D.; MANFRON, P.A.; LONDERO, F. Teor de nitrato em cultivares de alface produzidos em sistema convencional e hidropônico. Revista Insula, Florianópolis, n.32, p. 63-71. 2004.

REZENDE, A.J.; JUNQUEIRA, A.M.R.; XIMENES, M.I.N.; BORGO, L.A. Teores de nitrato em alface hidropônica produzida e comercializada no Distrito Federal. In: CONGRESSO BRASILEIRO DE OLERICULTURA, 39. 1999, Tubarão. Anais... Tubarão: Sociedade Brasileira de Olericultura, 1999, v. 1, n.307.

RICHARDSON, S.J.; HARDGRAVE, M. Effect of temperature, carbon dioxide enrichment, nitrogen form and rate of nitrogen fertilizer on the yield and nitrate content of two varieties of grasshouse lettuce. Journal of Science Food and Agriculture, Barking, v.59, p.345-349, 1992.

RUSCHEL, J. Acúmulo de nitrato, absorção de nutrientes e produção de duas cultivares de alface cultivadas em hidroponia, em função de doses conjuntas de nitrogênio e potássio. 1998. 76p. Dissertação (Mestrado em Agronomia) Escola Superior de Agricultura "Luiz de Queiroz"-USP, Piracicaba.

SANTAMARIA, P.; ELIA, A. Producing nitrate-free endive heads: effect of nitrogen form on growth, yield, and iron composition of endive. Journal of the American Society for Horticultural Science, Alexandria, v.1, n.122, p.140-145, 1997.

SANTOS, C.A.M.; TORRES, K.R.; LEONART, R. Plantas medicinais: herbarium flora et scientia. 2.ed. São Paulo: Ícone, 1988. 88p. (Coleção Brasil Agrícola)

SANTOS, O. Hidroponia da alface. 1.ed. Santa Maria: UFSM, 2000. 160p.

SGARBIERI, V.C. Alimentação e Nutrição: fator de saúde e desenvolvimento. 1.ed. Campinas: UNICAMP, 1987. 387p.

SWANN, P.F. The toxicology of nitrate, nitrite and N-nitrous compounds. Journal of the Science of Food and Agriculture, Barking, v.26, p.1761-1770, 1975.

VAN der BOON, J.; STEENHUIZEN, J.W.; STEINGRÖVER E.G. Growth and nitrate concentration of lettuce as affected by nitrogen and chloride concentration, $\mathrm{NH}_{4}^{+}: \mathrm{NO}_{3}^{-}$ratio and temperature of the recirculating nutrient solution. Journal of Horticultural Science, Alexandria, v.65, n.3, p.309-321, 1990.

WALKER, R. Nitrates, nitrites and N-nitroso compouds: a review of the occurrence in food and diet and the toxicological implications. Food Additivies and Contaminants, London, v.7, p.717-768, 1990

WOLFF, I.A.; WASSERMAN, A.E. Nitrates, nitrites, and nitrosamines. Science, Washington, v.177, p.15-19, 1972.

WRIGHT, M.J.; DAVINSON, K.L. Nitrate accumulation in crops and nitrate poisoning in animals. Advances in Agronomy, Sand Diego, v.16, p.197-274, 1964. 